\title{
Pseudomonas Aeruginosa: Virulence Factors and Antibiotic Resistance Genes
}

\author{
Antônio José Rocha* 1 \\ https://orcid.org/ 0000-0002-4358-4750 \\ Mario Ramos de Oliveira Barsottini ${ }^{2}$ \\ https://orcid.org/0000-0002-6461-5579 \\ Renan Rhonalty Rocha ${ }^{3}$ \\ https://orcid.org/0000-0001-9156-5661 \\ Maria Vitória Laurindo 4 \\ https://orcid.org/0000-0002-1268-3991
}

Francisco Leandro Laurindo de Moraes ${ }^{4}$

https://orcid.org/0000-0002-4536-7936

Soraya Lília da Rocha ${ }^{5}$

https://orcid.org/0000-0002-9130-9753

\begin{abstract}
1 Department of Biochemistry and Molecular Biology, Federal University of Ceará, Avenida Humberto Monte, 60440-900, Fortaleza, Ceará, Brazil; '2aboratory of Genome e BioEnergy-LGE. Institute of Biology, Campinas State University, Campinas, São Paulo, Brazil ${ }^{3}$ Laboratory de Microbiology-LABAM, Federal University of Ceará, Sobral, Ceará, Brazil; ${ }^{4}$ Faculty of center of UNINTA, Sobral, Ceará, Brazil; ${ }^{5}$ Laboratory of Environmental Biology and Microbiology -LABIAM, Federal Institute of Education, Science and Technology - IFCE - Campus Acaraú, Sobral, Ceará, Brazil
\end{abstract}

Received: 2018.09.18; Accepted: 2019.05.16.

* Correspondence: antonionubis@gmail.com, Department of Biochemistry and Molecular Biology, Federal University of Ceará, Avenida Humberto Monte, 60440-900, Fortaleza, Ceará, Brazil.

\section{HIGHLIGHTS}

- The bacterium has become the most antibiotic-resistant hospital disease

- P. aeuroginosa developed a mechanism antimicrobial against classes of $\beta$-lactamases

Abstract: In this review, we explore some aspects of Pseudomonas aeruginosa virulence factors that are related to disease development in healthy organisms and resistance to antibiotics. This pathogen is one of the most clinically and epidemiologically important bacteria in Brazil, being the major cause of opportunistic infections. Among the virulence factors, biofilm formation acting of manner different in the organism. Furthermore, we review several $P$. aeruginosa genes that act in antimicrobial resistance, such as $\beta$-lactamases against $\beta$-lactamers. The resistance to pied-lactamases in $P$. aeruginosa is associated to resistance to the broad-spectrum cephalosporin. On the other hand, there is a group of synthetic broad-spectrum antibiotics acting on DNA synthesis is the quinolones that destroy 
the microorganism. We also explore the occurence of super bacterium: $P$. aerufinosa carrying genes blaKPC and blaNDM, which are associated with patient death above the average of other bacterial infections in hospitals. Those genes encode carbapenemases that can potentially hydrolyse all $\beta$-lactam antibiotics

Keywords: Pseudomonas aeruginosa; virulence factors; antimicrobial activities; biofilms; $\beta$-lactamase

\section{INTRODUCTIION}

Pseudomonas aeruginosa is a Gram-negative, aerobic rodshaped bacterium, which belongs to the bacterial family Pseudomonadaceae, a member of $Y$-proteobacteria. $P$. aeruginosa is one of the subtypes among a group of 12 members (1). The pathogen is a free-living organism in diverse planktonic form environment. This pathogen also can form biofilm and is responsible for $10-20 \%$ of infections in hospitals [2].

Pseudomonas aeruginosa is one of the most clinically and epidemiologically important bacteria. It is the main cause of nosocomial infections among non-fermenting Gram-negative bacilli and the major cause of opportunistic infections in immunocompromised patients [3]. It is considered one of the main etiological agents of nosocomial infections in Brazil, $[4,5]$ and still is under continuous selective pressure in hospital settings $[4,6]$.

The development of different resistance mechanisms has a considerable clinical impact [3] since compromises the efficacy of nearly all drugs used as a treatment against $P$. aeruginosa, [7]. This results in a high cost of treatment for infected patients, [8] In addition to increased mortality and length of hospitalization [7]. The main resistance is due to the differential gene expression under stress conditions encoding genes responsible to obtain resistance to antimicrobial as $\beta$-galactamers, leading to very strenuous to suppress immunity when forming dense antibiotic-resistant biofilms, lowering the proficiency of immune systems in patients, as the organisms that exist in-group can endure some period of time [9].

At 6.3 million base pair (Mbp), $P$. aeruginosa genome is notably a large genome (encoding 5567 genes) compared to $4.64 \mathrm{Mbp}$ (4279 genes) in Escherichia coli K12, 2.81 Mbp (2594 genes). and Staphylococcus aureus N315, and $1.83 \mathrm{Mbp}$ (1714 genes) in Haemophilus influenza Rd. Futhermore, the proportion of predicted regulatory genes in $P$. aeruginosa genome is greater than all other sequenced bacterial genomes [9-11].

This review isfocused in the main targets genes involved in resistance of $P$. auruginosa to antimicrobial resistance in both free-living and the virulence factor responsible to cause phatogenicity by the $P$. aeruginosa in healthy organisms. The main virulence factor is the formation of the biofilm leading the identification of the genes differential expression during this diferents condition.

\section{Pseudomas aeruginosa: virulence factors that cause pathogenicity}

Several virulences may cause pathogenicity that facilitates adhesion and/or disrupt host cell signaling pathways while targeting the extracellular matrix. P.aeruginosa is capable 
of causing several deseases invading the organism and its immune system leading infecctions nearly impossible to eradicate [10-12]. Among the pathogenicity caused by virulence factors, can be cited Lipopolysaccharide, Flagellum, Type IV Pili, Type III Secretion System, Exotoxin A, Proteases, Alginate, Quorum Sensing, Biofilm Formation, Type VI Secretion Systems, Oxidant Generation in the Airspace. These are major virulence factors acting in different manners in the immune system.

The LPS is a predominant component of the outer membrane of $P$. aeruginosa. Bacterial LPS typically consists of a hydrophobic domain known as lipid A (or endotoxin), a non-repeating core oligosaccharide, and a distal polysaccharide (or O-antigen) [13]. LPS plays a prominent role in the activation of the host's innate (TLR4, NLRP1, NLRP2, and NLRP3) and adaptive (or acquired) immune responses; and, eventually causes dysregulated inflammation responses that contribute to morbidity and mortality [14].

In relation to virulence factors, the type IV pili of $P$. aeruginosa has a role in adhesion to many cell types and this is likely important in such phenomena as tissue tropism and attachment to particular tissues. The initiation of biofilm formation and non-opsonic phagocytosis ismediated by phagocyte receptors that recognize corresponding adhesions on microbial surfaces [15-19]. However, the virulence factors of Type III Secretion System provide a variety of secretion systems of which at least four likely play a role in virulence (Type I, II, III, and IV). The T3SS is one of the most intriguing virulence factors that involves a flagellum-basal-body related system for delivering proteins directly from the cytoplasm of $P$. aeruginosa into the cytosol of host cells that contributes to evasion of phagocytosis by $P$. aeruginosa as well as damage to host tissues, promoving a immune avoidance and bacterial dissemination $(20,21)$.

The virulence factors exotoxin A are secreted through Type II secretion mechanism, which use a pilus-like apparatus to secrete proteins into the extracellular environment, including lipase, phospholipase, alkaline phosphatase and protease. Animal experiments have indicated the significant role of these factors in model infection [22]. Besides, exotoxin $A$ has been demonstrated to be involved in local tissue damage and invasion [23].

Several proteases produced by $P$. aeruginosa as metaloproteases of type elastase LasB destroy host tissue; thus, it plays a significant role in both acute lung infections and burned wound infections [24]. Already the virulence factors alginate can produce a mucoid exopolysaccharide capsule, comprised of alginate, an acetylated random co-polymer of $\beta$ 1-4 linked D-mannuronic acid (poly-M) and L-guluronic acid [25]. The evidence of playing this role isbelieved due the overproduction of alginate in cell adherence within the CF lung and is thought to be involved in resistance to host defense by reducing susceptibility to phagocytosis [26].

The virulence factor Quorum sensing is a mechanism of bacterial "cell-to-cell" communication via diffusible chemical compounds. The Quorum is required to produce a sufficient amount of a secreted signal molecule (termed an autoinducer) to trigger expression of a large regulon [27]. In regarding to autoinducer, the most common class isused by Gram-negative bacteria and acyl-homoserine lactones (AHL). The mechanism is diffuse freely across bacterial membranes. AHL signals produced by $P$. aeruginosa are oxohexanoyl-homoserine lactone and butanoyl-homoserine lactone $(28,29)$. 
The AHL signals produced by AHL synthase (Lasl/Rhll) are diffused into the environment. The increase of bacterial density during infection leads to an increase in autoinducer concentration. In a determinated moment, autoinducer reaches a particular threshold and subsequently binds to transcriptional activator (LasR/RhIR) that forms a complex that activates genes involved in biofilm formation and coding virulence factors [30]. Biofilm formation starts with the attachment of free-swimming bacteria (planktonic) to a surface via their type IV pili and flagellum, followed by twitching motility and the formation of microcolonies; then quorum sensing signals begin to accumulate. Once a critical threshold of quorum sensing signals is reached, microcolonies become encased in an extracellular matrix [31]

In this review was described the biofilm formation that is also a virulence factor in the first topic. However, the last virulence factor discussed here is the Type VI Secretion Systems. Bacterial pathogens frequently possess numbers of secretion systems that function to translocate protein secretion. The T6SS represents one of the most recently recognized examples of these secretion systems. An interest in T6SS has led to its rapid study in $P$. aeruginosa in term of structure, mechanical function, assembly, and regulation of secretion $P$. aeruginosa T6SS provides defense against other bacteria in the environment [31-33]

\section{The Pseudomonas aeruginosa: the formation of the biofilm and resistance of the biofilm and free-live to antimicrobial}

Biofilms are communities composed of microorganisms adhered to a biotic or abiotic surface surrounded by a matrix of exopolysaccharide (EPS), whose function is to guarantee the protection of the microorganisms existing in its interior against the attack of the microbial aggressions of the external or internal environment. Thus, when $P$. aeruginosa is submitted under stress conditions, the formation of biofilms are often associated with higher antimicrobial resistance when compared to the planktonic form and assists in the evasion of the host immune response (31-36). Biofilm microorganisms also exhibit altered phenotype with respect to growth rate and gene transcription [35, 35].

$P$. aeruginosa is a Gram-negative bacillus involved in opportunistic diseases, particularly in immunocompromised patients, which may cause several diseases as dermatitis, urinary infections and a wide variety of systemic infections, especially in hospital infections [36]. The pathogenicity caused by $P$. auruginosa is a result of its phenotypic adaptability and its high degree of genomic flexibility. This microorganism increases its pathogenicity and synthesis of virulence factors. The $P$. aeruginosa is exposed to stress conditions and changes occur in its growth mode, generating biofilms (37). Thus, in promoting the growth of bacterial populations collectively, biofilms provide the species with adaptive mechanisms, such as the ability to synthesize signaling substances that mediate biofilm behavior as well as the synthesis of genes involved in protetion against antimicrobial, to adapt and become resistent to antimicrobial developed by the pharmaceutical industry. (37). 


\section{Mechanism of action of essential genes against antimicrobial activities}

Several mechanisms were developed by the $P$. aureginosa in order to be resistent to antimicrobial activities.Among $\beta$-lactam resistance mechanisms, the most important process is the production of $\beta$-lactamase enzymes; however, resistance can also be caused by hyperexpression of efflux systems, alteration of membrane permeability, as well as the synthesis of penicillin binding proteins (PBPs) with low affinity for $\beta$-lactams. In $P$. aeruginosa, all these mechanisms can exist simultaneously or isolated.

\section{Mechanism of potential genes target of $P$. aeuriginosa against $\beta$-lactamers antimicrobial}

The pathogen $P$. aeuroginosa developed a mechanism antimicrobial against classes of $\beta$-lactamases [38] and a significant number of different classes are found in $P$. aeruginosa. The $\beta$-lactamases are capable of inactivate the $\beta$-lactam antimicrobials by ring breaking $\beta$-lactam, disrupting its amide bond, so the products obtained cease to have antibacterial activity as showed in figure 1 [39].

\section{B-Lactam Antibiotics}
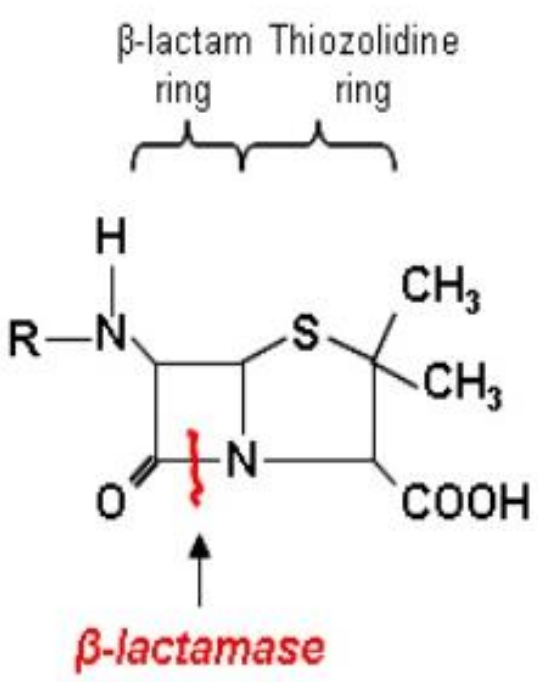

Penicillins
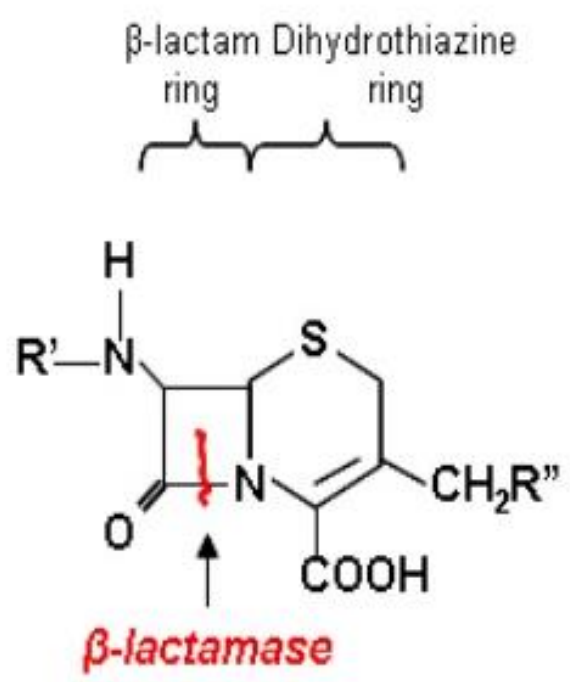

\section{Cephalosporins}

Figure 1- $\beta$-lactamases breaking of the $\beta$-lactam ring $\beta$-lactam antibiotics that inactivate $\beta$-lactam antibiotic, breaking its amide bond, so the obtained products stopped antibacterial activity wih class of penicilins and cephalosporins.

The hydrolysis of antibiotics by the $\beta$-lactamase activity occurs by the formation of an ester bond between the active serine site (or with zinc ions in the case of the metallo- $\beta$-lactamases) of the $\beta$-lactamase enzyme and the $\beta$-lactam ring of the antimicrobial $[39,40]$

The enzymes of the $P$. aeruginosa that break the $\beta$-lactam ring are located in the periplasmic space and inactivate $\beta$-lactams, in which pass through the outer membrane, 
before they reach the PBPs. (Livermore et al, 2002). Several genes encoding $\beta$-lactamase enzymes are located in mobile regions of bacterial DNA, such as plasmids and (class 1 integrons, however some are found in the class 2 and 3 integrins) [38-40].

The $\beta$-lactamases class of genes encoding specific enzymes of Pseudomonas aeruginosa (PSES)

The $\beta$-lactamases are the specific enzymes of Pseudomonas (PSEs) PSE- 1 and PSE-4. In Ambler's class A, within Bush's functional group 2c, four PSE-type $\beta$-lactamases that hydrolyze carbenicillin were found in $P$. aeruginosa: PSE-1 (CARB-2), PSE-4 (CARB-1), CARB-3 and CARB-4; its substrate of PSEs includes several antimicrobial as carboxypenicillins, ureidopenicillins and cefsulodine. The presence of PSEs can be bypassed, since strains producing carbenicillinases present variable susceptibility to cefepime, cefpirome and aztreonam and total susceptibility to ceftazidime and carbapenems [37-39]. Genes similar to PSE-4 are part of transposons containing several genes that are encoding enzymes of the resistance that encodes PSE-4 enzymes.

Strateva et al [38] also concluded that to PSEs, broad-spectrum $\beta$-lactamases (ESBLs) of molecular class $A$ and functional group $2 b$ 'lead to the development of resistance not only to carboxypenicillins and ureidopenicillins, but also to broad spectrum efalosporins. These enzymes may have a wider hydrolytic activity, including over carbapenems, although almost all are inhibited by clavulanic acid. The frequency of ESBLs, widely reported in enterobacteria, has increased in $P$. aeruginosa isolates.

On the other hand, there is an ezyme encondig the gene AmpC of Ambler's class A denominated cephalosporins. This occurs by the superexpression in the bacteria causing stable derepression; this mechanism is frequently responsible for resistance to third generation cephalosporins. The resistance to pied-lactamics in $P$. aeruginosa is associated to resistance to $\beta$-lactamics and this antmicrobial big spectrum as cefalosporins. B-lactamase inhibitors in clinical practice, such as clavulanic acid, sulbactam and tazobactam (Livermore et al, 2002), do not inhibit the activity of AmpC.

Strateva et al, [38] also investigated that other type of Class $D \beta$-lactamases is constituted by ESBLs of type OXA-18, OXA-2, OXA-10 (PSE-2), OXA-21, ARI-1 (Acinetobacter Resistant to Imipenem). The classical OXA (OXA-1, OXA-2, OXA-10) enzymes determine resistance to carboxypenicillins and ureidopenicillins, but not to ceftazidime. Therefore, oxacillinases that hydrolyze ceftazidime have the highest clinical importance. Its hydrolytic spectrum also includes cefotaxime, cefepime, cefpirome, aztreonam and moxalactam.

With the exception of OXA-18, which is totally inhibited by clavulanic acid and whose hydrolytic properties resemble those of class A ESBLs, $\beta$-lactamase inhibitors do not suppress the activity of these enzymes. Although the $\beta$-lactamases of Ambler families $A, C$ and $D$ use a serine residue as nucleophile for catalysis, the metallo- $\beta$-lactamases (MBLs), inserted into class B of Ambler and class 3 of Bush-Jacoby- Medeiros, use divalent cations, generally, $\mathrm{Zn}^{+2}$, as cofactor for their catalytic activity. Another characteristic that differentiates $M \beta L$ s from serine- $\beta$-lactamases is the low susceptibility to $\beta$-lactamase inhibitors (tazobactam, sulbactam and clavulanic). Furthermore, MßLs that have activity 
against carbapenems do not hydrolyze monobaccharides, such as aztreonam are inhibited by chelating agents [39-40].

\section{Ciprofloxacin and resistance mechanisms}

Quinolones are a group of synthetic broad-spectrum antibiotics acting on DNA synthesis to destroy the microorganism. They have been widely used for the treatment of intra- and extra-hospital infections, making it a very important resource for developing countries because of the high availability of generics that drastically reduce the cost of treatment $[34,41]$.

The specific target of the quinolones occurs through the interference of DNA synthesis, leading to bacterial cell death by chromosome fragmentation. It penetrates into the cell wall through porins, directly inhibiting bacterial replication. The interacting with two enzymes: DNA-gyrase (tetrameric protein composed of two pairs of $A$ and $B$ subunits encoded by GyrA and GyrB genes) and topoisomerase IV (tetrameric protein composed of two pairs of subunits $A$ and $B$ encoded by parc and Par $E$ genes), both are required to perform DNA supercoiling. Thus, specifically, DNA-gyrase is the primary target in Gram-negative bacteria, whereas topoisomerase IV is in Gram-positive bacteria. However, there are quinolones with enhanced activity and potency spectrum and appear to target both enzymes (42-43).

There are different mechanisms of resistance in quinolones; the main ones for Gram-negative, as $P$. aeruginosa: 1) mutation in target sites / regions quinolone resistance-determining region (QRDR), 2) transmission of plasmid resistance genes, called plasmid (3) changes in membrane permeability and (4) efflux mechanism (Fig. 2) [44-46].

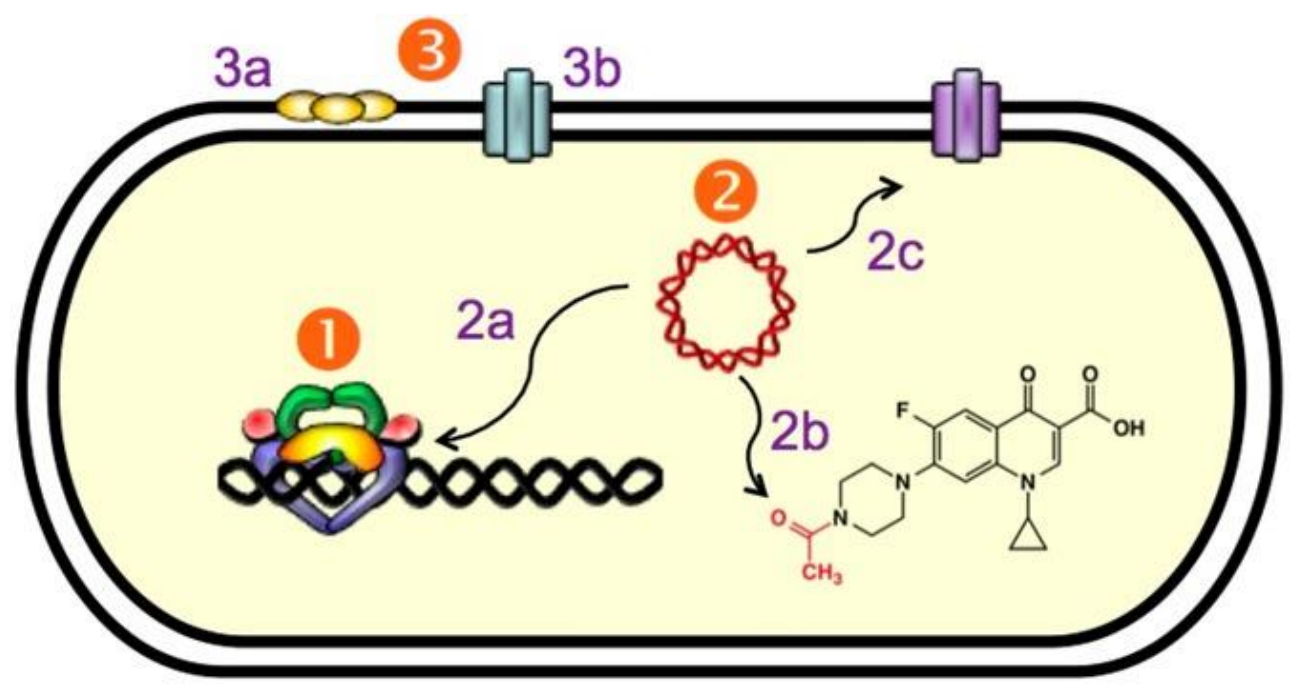

Figure 2 - Quinolone resistance systems in bacterial cell: (1) Resistance mediated by mutations in the genes of the enzymes DNA gyrase and topoisomerase IV, which decrease antibiotic binding. (2) Plasmid gene mediated resistance: (2a) Qnr proteins (in yellow), which inhibit binding of quinolone to the DNA-topoisomerase complex; (2b) The enzyme AAC (6 ') - Ib-cr, which acetylates some quinolones reducing its efficacy; (2c) Membrane expulsion systems, which decrease the intracellular concentration of the quinolones. (3) Resistance mediated by chromosomal genes: (3a) Decreased 
expression of porins, which limits the entry of the antibiotic; (3b) Ejection systems. ALDRED; KERNS; OSHEROFF, 2014 (adapted).

Thus, the antibiotic of the quinolone class that has shown the greatest resistance to Gram-negative is ciprofloxacin. Even after 20 years of launch and success, it remains the most prescribed and recommended in the treatment of community urinary tract infections, and therefore, the most exposed to these bacteria [45-46]. However, its use on a large scale can generate problems not only with regard to the resistance acquired by pathological microorganisms during a clinical treatment, but also represent a significant risk to the environment [47, 48].

The substance ciprofloxacin, wich has the chemical name of 1-cyclopropyl-6-fluoro-1,4-dihydro-4-oxo-7- (1-piperazinyl) -3-quinoline carboxylic acid hydrochloride, has its chemical structure shown in figure 3.
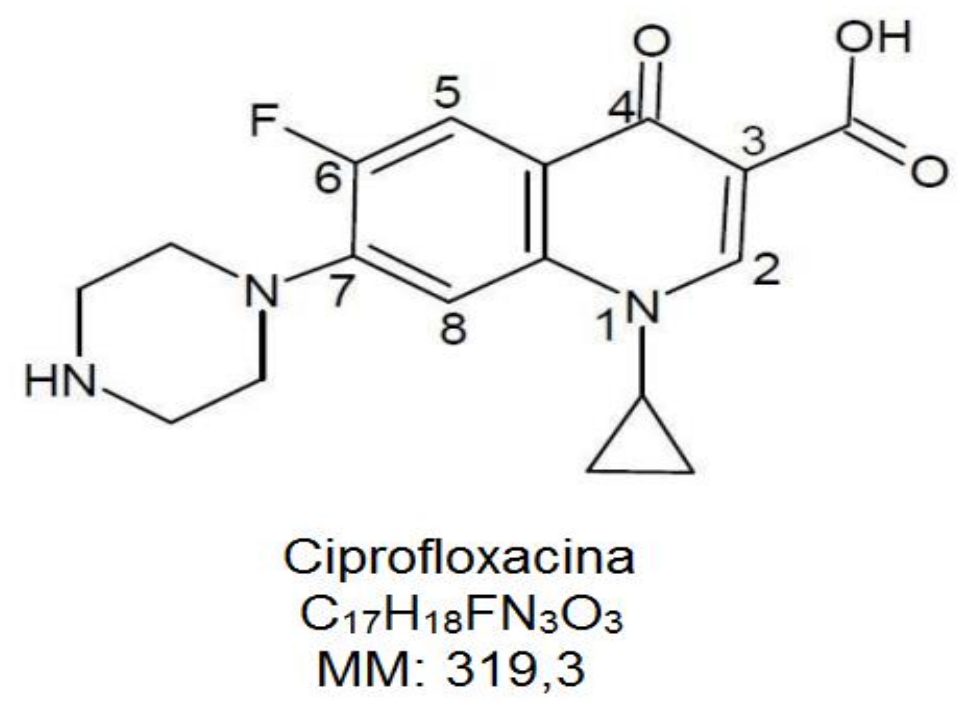

Figure 3 - Chemical structure of ciprofloxacin.. MM: Molar Mass. ZANCHETTA; PENA; performed by GONÇALVES, 2015 Adaptad

In fluoroquinolones, the presence of the piperazino group confers antipseudomonas activity, whereas the fluorine atom increases the potency against Gram-negative species in general and broadens its action spectrum including Gram-positive species. Thus, they are active against a wide variety of 21 aerobic microorganisms. They are, therefore, broad-spectrum anti-infectives. However, they are generally inactive against anaerobic bacteria [50].

\section{Mechanism of potential genes target of $\boldsymbol{P}$. aeuriginosa throug to Pump eflux}

The most common form of resistance to most classes of antibiotics is throug pump antibiotics out of cells. [51] In $P$. aeruginosa, active efflux is an important non-enzymatic mechanism of resistance to $\beta$-lactams. In addition to antibiotics, biocides and detergents, these pumps export several other molecules. [51] The expression of efflux pumps is one of 
the mechanisms responsible for antimicrobial resistance in biofilms. [52] As presented in figure 4 .

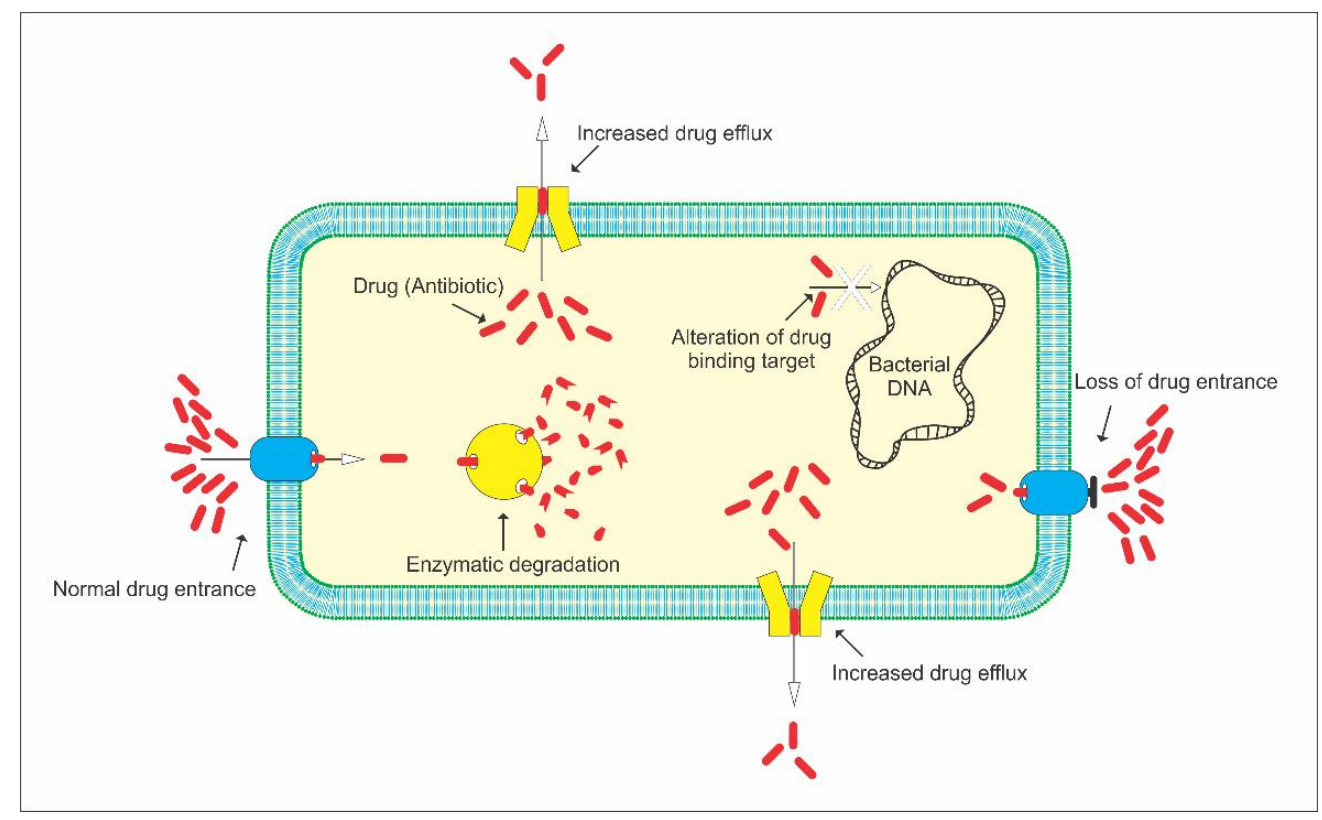

Figure 4-Schematic diagram highlighting the antibiotic resistance mechanism utilized the efflux pump in biofilms. MDR pathogens can employ one or more of these mechanisms to become resistant to a diverse array of antibiotics. This figure appears in colour in the online version of JAC and in black and white in the print version of JAC. This figure reported by Skariyachan et al, 2018 adapted

The efflux systems are classified into six families: major facilitator superfamily (MFS), ATP-binding cassette (ABC) superfamily, small multidrug resistance (SMR) family, resistance splitting division (RND) superfamily, multidrug and toxic compound extrusion and drug metabolite transporter (DMT) superfamily.[53, 54] The most clinically relevant efflux systems in Gram-negative bacteria are those of the RND family. Several of them are expressed by $P$. aeruginosa. Among them, MexA-MexB-OprM, MexC-MexD-OprJ, MexEMexF-OprN and MexX-MexY-OprM are significant determinants for resistance to various drugs. These pumps are systems with three components. The first component is a protein located in the cytoplasmic membrane (MexB, MexD, MexF and MexY), which operates as an energy dependent pump with broad substrate specificity. The second component is an outer membrane protein, a porin (OprM, OprJ and OprN). The third protein are (MexA, MexC, MexE and MexX) [55].

The multidrug efflux system of the RND type in $P$. aeruginosa, the MexABOprM, removes $\beta$-lactams, chloramphenicol, macrolides, novobiocin, sulfonamides, tetracycline etrimethoprim, as well as various dyes and detergents [56]. MexAB-OprM is the most common efflux system, and its overexpression results in resistance to quinolones, penicillins and cephalosporins.

De Kievit et al [54], investigated the expression of genes associated with two multidrug resistance (MDR) efflux pumps, MexAB-OprM and MexCD-OprJ, throughout the course of biofilm development. Using fusions to GFP, we were able to analyze spatial and temporal expression of mexA and mexC in the developing biofilm. The results showed that the 
expression of mexAB-oprM and mexCD-oprJ was not upregulated but rather decreased over time in the developing biofilm.

Northern blot analysis confirmed that these pumps were not hyperexpressed in the biofilm. Furthermore, spatial differences in mexAB-oprM and mexCD-oprJ expression were observed, with maximal activity occurring at the biofilm substratum. Using a series of MDR mutants, assessed the contribution of the MexAB-OprM, MexCD-OprJ, MexEF-OprN, and MexXY efflux pumps to P.aeruginosa biofilm resistance. These analyses led to the surprising discovery that the four characterized efflux pumps do not play a role in the antibiotic-resistant phenotype of $P$. aeruginosa biofilms [10]. The position of the genes encoding the multiple efflux (mex) components of four characterized pumps (mexAB, mexCD, mexEF and mexXY) are shown together with their respective porin (opr) components, oprM and oprJ and oprN. The position of the chromosomal b-lactamase gene $(\mathrm{ampC})$ and its regulatory gene $(\mathrm{ampR})$ also shown in figure 5 below.

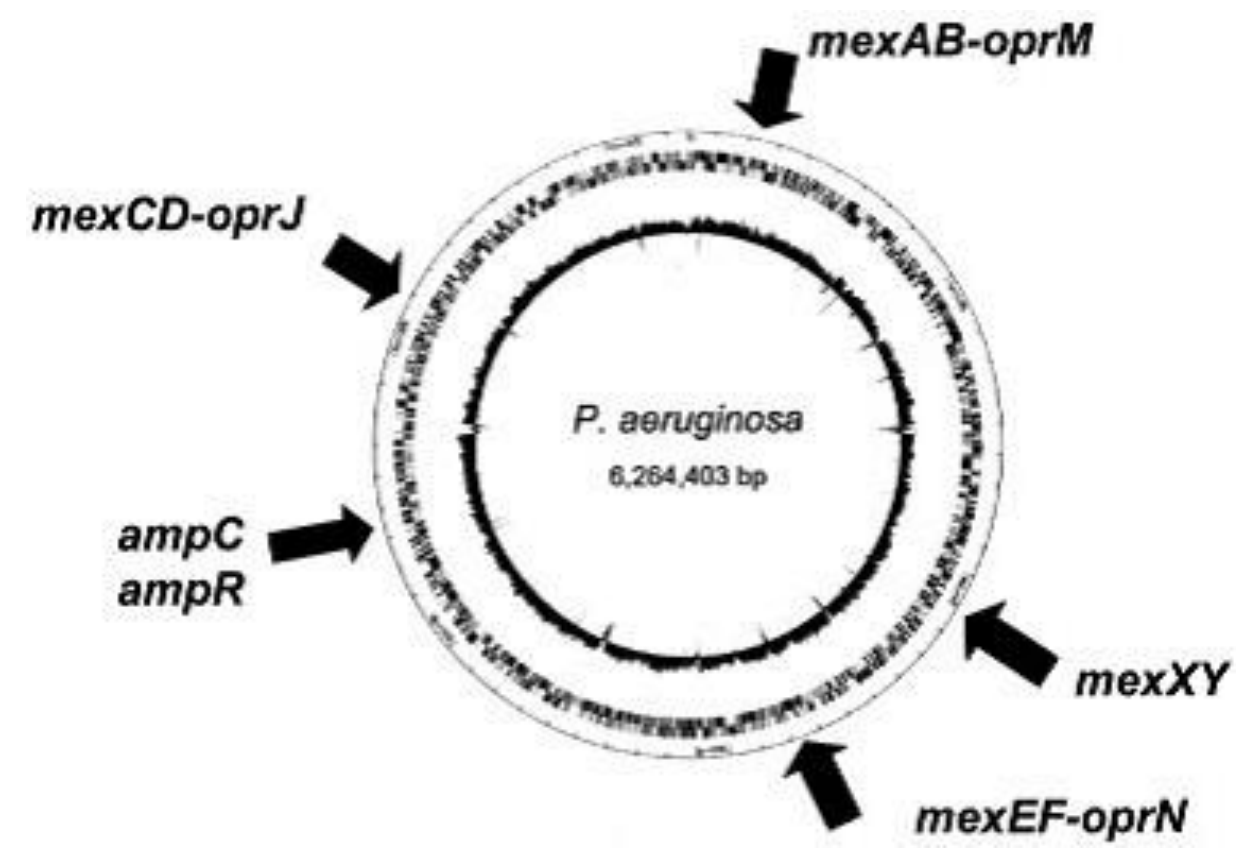

Figure5. The Location of efflux and chromosomal $b$-lactamase genes on the genome of $P$. aeruginosa PAO1 (Pseudomonas Genome Project [http://www.pseudomonas.com]), in which were reported by Lambert et al, 2002 adaptad

All classes of antibiotics except the polymyxins are susceptible to extrusion by one or more of the efflux systems. MexAB-oprM is responsible for extrusion of b-lactams, quinolones and a range of disinfectants. MexXY-oprM extrudes aminoglycosides and mexEF-oprN extrudes carbapenems and quinolones. Besides, the genes for the systems are present in all strains, but they are not expressed at high levels. However, increased expression can result from mutation in regulatory genes such as mexR, which controls expression of the mexAB-oprM genes [55-58].

Vahaboglu et al, [56] has investigated beta-lactamase (PER-1-type)-producing Acinetobacter spp. and Pseudomonas aeruginosa strains. The result revealed that over-production of the ampC b-lactamase poses a particular threat to cephalosporins. Other b-lactamases produced by $P$. aeruginosa include extended-spectrum plasmid-mediated 
enzymes (ESBLs) active against penicillins and cephalosporins. Nevertheless, the use of b-lactamase inhibitors (clavulanic acid with ticarillin and tazobactam withPiperacillin) provides protection of these antibiotics against some of the plasmid-mediated enzymes, but not the ampC.

Taylor et al [57] has analysed the antibiotic resistance in Pseudomonas aeruginosa biofilms: Towards the development of novel anti-biofilm therapies e conclude in your work because of this highly adapted ability to survive in adverse environmental conditions, bacterial biofilms are recalcitrant to antibiotic therapies and immune clearance. This is particularly problematic in hospital settings where biofilms are a frequent cause of chronic and device-related infections and constitute a significant burden on the health-care system. These biofilms are able of expressing potential genes for increasing the resistance of $P$. auriginosa to attack of antimicrobial, leading to acquire an adaptive resistance that is becoming increasingly recognized as a clinical important mechanism of resistance to antimicrobial.

Zhang et al, [58] has identified involvement in $P$. aeruginosa with biofilm-specific resistance to antibiotics. The authors identified 3 genes or operons of $P$. aeruginosa UCBPP-PA14 (ndvB,PA1875-1877 and tssC1) that do not affect biofilm formation, but are involved in biofilm-specific antibiotic resistance. In this study, they demonstrated that PA0756-0757 is encoding a putative two-component regulatory system. PA2070 andPA5033 showed increased expression in biofilm cells. They also have a role in biofilm-specific antibiotic resistance. Furthermore, deletion of each PA0756, PA2070 and PA5033 resulted in a significant reduction of lethality in Caenorhabditis elegans, indicating a role for these genes in both biofilm-specific antibiotic resistance and persistence in vivo.

\section{Super Bacteria: blaKPC and blaNDM genes}

As a matter of course, since 2010, the Brazilian media has used the term "KPC superbug" (as well as "NDM superbug"). In the lay context, it refers to the bacteria that has caused deaths of patients above the average of other bacterial hospital infections, associated or not to outbreaks. Scientifically, in the clinical and microbiological context, as presented, KPC and NDM are carbapenemases (beta-lactamases enzymes) that have the potential for hydrolysis (degradation) of practically all beta-lactam antibiotics. The blaKPC and blaNDM genes have presented great potential for dissemination, characteristic associated with mobile genetic elements (eg plasmids) and high bacterial clones [59-60].

\section{CONCLUDING REMARKS}

Several groups of scientists have developed various drugs with varied mechanisms of action to combat the antimicrobial resistance caused by P. aeruginosa. The bacterium has become the most antibiotic-resistant hospital disease in the pharmaceutical industry. Due this problem, researchers have been trying to find new drugs capable of stopping the microbial infection caused by $P$. aeruginosa, which has shown resistance to most antibiotics. The challenge now is to reverse this clinical problem and eradicate the infection caused by $\mathrm{P}$. aeroginosa with new drugs with potential antimicrobials capable of curing patients with this disease. 


\section{ACKNOWLEDGEMENTS}

The authors are greateful to the Universidade Federal do Ceará-UFC, CNPq and CAPES

\section{CONFLICTS OF INTEREST}

There are not any conflicts of interest related to this manuscript.

\section{REFERENCES}

1. Todar, K. Todar's online textbook of bacteriology. University of Wisconsin-Madison Department of Bacteriology 2008.

2. Fazeli H, Akbari R, Moghim S, Narimani T, Arabestani MR, Ghoddousi AR. Pseudomonas aeruginosa infections in patients, hospital means, and personnel's specimens. J Res Med Sci 2012 17(4):332-3372.

3. Kollef $\mathrm{MH}$. Antibiotics for the critically ill: more than just selecting appropriate initial therapy. Crit Care. 2013 2; 17 (3):146.

4. Boucher HW, Corey R. Epidemiology of Methicilin - Resistant staphylococcus aureus. Clin Infect Dis. 2008;46 (Supplement 5):S344-S349.

5. Tavares, W. Bactérias gram-positivas problemas: resistência do estafilococo, do enterococo e do pneumococo aos antimicrobianos. Rev Soc Bras Med Trop. 2000 33; (3):281-301.

6. Zarychanski R, Ariano RE, Paunovic B, Bell DD. Historical perspectives in critical care medicine: blood transfusion, intravenous fluids, inotropes/vasopressors, and antibiotics. Crit Care Clin. 2009 25; (1):201-20.

7. Gonzalez L, Cravoisy A, Barraud D, Conrad M, Nace L, Lemarie J, et al. Factors influencing the implementation of antibiotic deescalation and impact of this strategy in critically ill patients. CritCare 2013 17; (4):R140.

8. Henkin CS, Coelho JC, Paganella MCI, Siqueira RM, Dias FS. Sepse: uma visão atual. Sci Med. 2009 19; (3):134-45.

9. Alayande AB, Aung MM, Kim IS. Correlation Between Quorum Sensing Signal Molecules and Pseudomonas aeruginosa's Biofilm Development and Virulency, Current Microbiology 2018 75:787-793

10. Skariyachan S, Sridhar VS, Packirisamy S, Kumargowda ST, Challapilli SB. Recent perspectives on the molecular basis of biofilm formation by Pseudomonas aeruginosa and approaches for treatment and biofilm dispersal. Folia Microbiologica 2018; 63:413-432

11. Laverty G, Gorman SP, Gilmore BF Biomolecular mechanisms of Pseudomonas aeruginosa and Escherichiacoli biofilm formation.Pathogens 2014 3; (3):596-632.

12. Lambert, P. A. Mechanisms of antibiotic resistance in Pseudomonas aeruginosa. J. R. Soc. Med. 2002 95(Suppl 41): 22-26.

13. Pier GB, Ramphal R. Pseudomonas aeruginosa. In G. L. Mandell \& J. E. Bennett (Ed.), Mandell, 2005.

14. Mandell G, Bennett J, Dolin R. principles and practice of infectious diseases 7 Th Edition. Elsevier/Churchill Livingstone, New York, 2009.

15. Raetz CR, Whitfield C. Lipopolysaccharide endotoxins. Annu Rev Biochem 2002 71: 635-700.

16. Köhler T, Curty LK, Barja F, Van Delden C, Pechère JC. Swarming of Pseudomonas aeruginosa is dependent on cell-to-cell signaling and requires flagella and pili. Journal of bacteriology 2000 182; (21): 5990-5996.

17. Doring G, Pier GB. Vaccines and immunotherapy against seudomonas aeruginosa. Vaccine 2008 26; (8):1011-24

18. Barken KB, Pamp SJ, Yang L, Gjermansen M, Bertrand JJ, Klausen M, et al. Roles of type IV pili, flagellum-mediated motility and extracellular DNA in the formation of mature multicellular structures in Pseudomonas aeruginosa biofilms. Environmental microbiology 2008 10; (9): 2331-2343. 
19. Mahenthiralingam E, Speert DP. Nonopsonic phagocytosis of Pseudomonas aeruginosa by macrophages and polymorphonuclear leukocytes requires the presence of the bacterial flagellum. Infect Immun 1995 63; (11): 4519-23.

20. Punsalang AP, Sawyer, W. D. Role of pili in the virulence of Neisseria gonorrhoeae. Infection and immunity 1973 8;(2): 255-263.

21. Frank, DW. The exoenzyme $S$ regulon of Pseudomonas aeruginosa. Mol Microbiol, 26, 621-9. 21-Goranson, J., Hovey, A. K., \& Frank, D. W. Functional analysis of exsC and exsB in regulation of exoenzyme $S$ production by Pseudomonas aeruginosa. Journal of bacteriology 1997 179; (5): 1646-1654.

22. Passador, L, Iglewski, W. ADP-ribosylating toxins. Methods Enzymol 1994, 235: 617-31.

23. Iglewski, BH, Liu, PV, Kabat, D. Mechanism of action of Pseudomonas aeruginosa exotoxin Aiadenosine diphosphate-ribosylation of mammalian elongation factor 2 in vitro and in vivo. Infection and immunity 1977 15; (1): 138-144.

24. Bielecki P, Glik J, Kawecki M, VA, MS. Towards understanding Pseudomonas aeruginosa burn wound infections by profiling gene expression 2008 30; (5):777-90.

25. Pier, GB, Coleman F, Grout M., Franklin M, Ohman DE. Role of alginate O acetylation in resistance of mucoid Pseudomonas aeruginosa to opsonic phagocytosis. Infection and immunity 2001 69; (3): 1895-1901.

26. Diggle SP, Cornelis P, Williams P, Camara M. 4-quinolone signalling in Pseudomonas aeruginosa: old molecules, new perspectives. Int J Med Microbiol 2006296 (2-3): 83-91.

27. Pearson J P, Gray KM, Passador L, Tucker KD, Eberhard A, Iglewski BH, et al. Structure of the autoinducer required for expression of Pseudomonas aeruginosa virulence genes. Proceedings of the National Academy of Sciences 2001 91; (1): 197-201.

28. Pearson, J. P., Passador, L., Iglewski, B. H., \& Greenberg, E. P. A second N-acylhomoserine lactone signal produced by Pseudomonas aeruginosa. Proceedings of the National Academy of Sciences 1995 92; (5): 1490-1494.

29. Hirakawa, H, Tomita $\mathrm{H}$. Interference of bacterial cell-to-cell communication: a new concept of antimicrobial chemotherapy breaks antibiotic resistance. Frontiers in microbiology 2013 4; 114 : $1-14$.

30. Hauser A. R. The type III secretion system of Pseudomonas aeruginosa: infection by injection. Nature Reviews Microbiology 2009 7; (9): 654-665.

31. Skariyachan S, SridharVS, Packirisamy S, Kumargowda ST, Challapilli SB. Recent perspectives on the molecular basis of biofilm formation by Pseudomonas aeruginosa and approaches for treatment and biofilm dispersal. Folia Microbiologica 2018 63; (4):413-432.

32. Ho BT, Dong TG, Mekalanos JJ A view to a kill: the bacterial type VI secretion system. Cell host \& microbe $201415 ;(1)$ : 9-21.

33. Miguel JC, Costa JC, Espeschit IF, Pieril FA, Benjamin, MAC Moreira. Increase in biofi Im formation by Escherichia coli under conditions that mimic the mastitic mammary gland. Ciência Rural, 2014 44; 4: 666-671, 2014.

34. -Williamson KS, Richards LA, Perez-Osorio AC, Pitts B, Mclnnerney K, Stewart PS, et al. Heterogeneity in Pseudomonas aeruginosa biofilms includes expression. of ribosome hibernation factors in the antibiotic-tolerant subpopulation and hypoxia-induced stress response in the metabolically active population. Journal of Bacteriology 2012 194; 8: 2062-2073.

35. Pedrosa AP, Brandão MLL, Medeiros VM, Rosas CO, Bricio SML, Almeida AECC. Pesquisa de fatores de virulência em Pseudomonas aeruginosa isoladas de águas minerais naturais. Ambiente \& Água - An Interdisciplinary Journal of Applied Science 2014 9; 2: 313-324.

36. Haüssler S, Becker T. The Pseudomonas Quinolone Signal (PQS) balances life and death in Pseudomonas aeruginosa populations. PLOS Pathogens Journal Information 2008 4; 9: 1-8.

37. Davies J, Davies D. Origins and evolution of antibiotic resistance. Microbiol Mol Biol Rev. 2010 74; (3):417-33.

38. Strateva T, Yordanov D. Pseudomonas aeruginosa - a phenomenon of bacterial resistance. $\mathrm{J}$ Med Microbiol. 2009 58; (9):1133-48.

39. Livermore DM. Multiple mechanisms of antimicrobial resistance in Pseudomonas aeruginosa: our worst nightmare? Clin Infect Dis. 2002 34; (5): 634-40. 
40. Pallecchi L, Bartoloni A, Riccobono E, Fernandez C, Mantella A, Magnelli D et al. Quinolone resistance in absence of selective pressure: the experience of a very remote community in the Amazon forest. PLoS Negl Trop Dis 2012 6; 8: e1790.

41. Pereira MSV, Siqueira Júnior JP, Takaki GMC. Revisão sistemática das mutações da girase associada ao Mycobacterium tuberculosis resistente à fluoroquinolona e proposta de sistema de numeração da girase. J Antimicrob Chemother 2012 67; 4: 819-31.

42. Chavez-Jacobo VM, Ramirez-Diaz MI, Silva-Sanchez JY, Cervantes C.Resistencia Bacteriana a Quinolonas: Determinantes Codificados en Plásmidos. Rev. educ. bioquímica 2015 34; 1: 4-9.

43. Redgrave LS, Sutton SB, Webber MA, Piddock LJ. Fluoroquinolone resistance: mechanisms, impact on bacteria, and role in evolutionary success. Trends in Microbiology 2014 22; 8: 438-444.

44. Iniz AMM, Santos RMC. Escherichia coli Resistente a Ciprofloxacina em Pacientes Internados em Hospital Universitário de Manaus 2015 Revista de Epidemiologia e Controle de Infecção 2017 7;1: 20-24.

45. Aldred KJ, Kerns RJ. Osheroff, N. Mecanismo de ação e resistência às quinolonas. Bioquímica 2014 53; 10: 1565-1574.

46. Silva FC, Costa GS, Grilo JHR, Silva BM. Análise da resistência às quinolonas e sulfametoxazoltrimetoprim em uroculturas positivas para Escherichia coli em infecções do trato urinário comunitárias no período de 2010 a 2014 em Itajubá - MG. Revista Ciências em Saúde 2017 7;1:1-7.

47. Marti E, Huerta B, Rodríguez-Mozaz S, Barceló D, Jofre J, Balcázar JL. Characterization of ciprofloxacin-resistant isolates from a wastewater treatment plant and its receiving river. Water Research 2014 15; 61:67-76.

48. Zanchetta PG, Pena A, Gonçalves RF. Desenvolvimento e validação de método para quantificação simultânea de ofloxacina, norfloxacina e ciprofloxacina em urina humana. Eng Sanit Ambient 2015 20; 2: 307-314.

49. 14 Soto SM. Role of efflux pumps in the antibiotic resistance of bactéria embedded in a biofilm. Virulence 2013 1; 4(3): 223-229.

50. Percival SL, Suleman L, Vuotto C, Donelli G. Healthcare-associated infections, medical devices and biofilms: risk, tolerance and control. J Med Microbiol 2015 64; (4):323-34.

51. Stapleton F, Dart J. Pseudomonas keratitis associatedwith biofilmformation on a disposable soft contact lens. Br J Ophthalmol 1995 79; (9): 864-865

52. Flemming HC, Wingender J. The biofilm matrix. Nat Rev Microbiol 2010 8; (9):623-33

53. Cryer J, Schipor I, Perloff JR, Palmer JN. Evidence of bacterial biofilms in human chronic sinusitis. ORL JOtorhinolaryngol Relat Spec 2004 66; (3):155-8.

54. De Kievit TR, Parkins MD, Gillis RJ Srikumar R, Ceri H, Poole K, Iglewski BH, et al..Multidrug efflux pumps: expression patterns and contribution to antibiotic resistance in Pseudomonas aeruginosa biofilms. Antimicrob Agents Chemother 2001 45; (6):1761-70.

55. Ziha-Zarifi I, Llanes $C$, Köhler T, Pechere JC, Plesiat P. In vivo emergence of multidrug-resistant mutants of Pseudomonas aeruginosa overexpressing the active efflux system MexA-MexB-OprM. Antimicrob. Agents Chemother 1999 43; (2): 287-291.

56. Vahaboglu H1, Coskunkan F, Tansel O, Ozturk R, Sahin N, Koksal I. Clinical importance of extended-spectrum beta-lactamase (PER-1-type)-producing Acinetobacter spp. and Pseudomonas aeruginosa strains. J Med Microbiol 2001 50; (7): 642-5.

57. Taylor PK, Yeung TYA, Hancock, REW. Antibiotic resistance in Pseudomonas aeruginosa biofilms: Towards thedevelopment of novel anti-biofilm therapies. Journal of Biotechnology 2014 191: 121-130.

58. Zhang L, Fritsch M, Hammond L, Landreville R, Slatculescu C, Colavita A, et al. Identification of Genes Involved in Pseudomonas aeruginosa Biofilm-Specific Resistance to Antibiotics. PLoS One 2013 24; 8: (4) e61625.

59. Weiß D, Engelmann I, Braun SD, Monecke S, Ehricht R. A multiplex real-time PCR for the direct, fast, economic and simultaneous detection of the arbapenemase genes blaKPC, blaNDM, blaVIM and blaOXA-48. Journal of Microbiological Methods 2017 142: 20-26. 
60. Chávez-Jacobo VC, Karen C. Ramírez H, Romo-Rodríguez P, Pérez-Gallardo RV, CamposGarcía J, et al. CrpP Is a Novel Ciprofloxacin-Modifying Enzyme Encoded by the Pseudomonas aeruginosa pUM505 Plasmid. 2018 62; (6): 02629-17.

(C) 2018 by the authors. Submitted for possible open access publication under the terms and conditions of the Creative Commons Attribution (CC BY NC) license (http://creativecommons.org/licenses/by-nc/4.0/). 